\title{
The mTOR-S6 kinase pathway promotes stress granule assembly
}

\author{
Aristeidis P. Sfakianos ${ }^{1} \cdot$ Laura E. Mellor $^{1} \cdot$ Yoke Fei Pang ${ }^{1} \cdot$ Paraskevi Kritsiligkou (iD ${ }^{1} \cdot$ Hope Needs (1) ${ }^{1}$. \\ Hussein Abou-Hamdan ${ }^{2} \cdot$ Laurent Désaubry $^{2} \cdot$ Gino B. Poulin ${ }^{1} \cdot$ Mark P. Ashe $^{1} \cdot$ Alan J. Whitmarsh ${ }^{1}$
}

Received: 14 July 2017 / Revised: 20 December 2017 / Accepted: 10 January 2018 / Published online: 9 March 2018

(c) The Author(s) 2018. This article is published with open access

\begin{abstract}
Stress granules are cytoplasmic mRNA-protein complexes that form upon the inhibition of translation initiation and promote cell survival in response to environmental insults. However, they are often associated with pathologies, including neurodegeneration and cancer, and changes in their dynamics are implicated in ageing. Here we show that the mTOR effector kinases S6 kinase 1 (S6K1) and S6 kinase 2 (S6K2) localise to stress granules in human cells and are required for their assembly and maintenance after mild oxidative stress. The roles of S6K1 and S6K2 are distinct, with S6K1 having a more significant role in the formation of stress granules via the regulation of eIF2 $\alpha$ phosphorylation, while S6K2 is important for their persistence. In C. elegans, the S6 kinase orthologue RSKS-1 promotes the assembly of stress granules and its loss of function sensitises the nematodes to stress-induced death. This study identifies S6 kinases as regulators of stress granule dynamics and provides a novel link between mTOR signalling, translation inhibition and survival.
\end{abstract}

\section{Introduction}

Cells employ a number of mechanisms to adapt and survive stressful conditions [1,2]. Many stresses cause repression of translation coincident with the formation of stress granules (SGs) [3, 4]. This is primarily mediated by the phosphorylation of translation initiation factor 2 alpha (eIF2 $\alpha$ ) by stress-responsive protein kinases [3-5]. Independent of this, SGs are induced by the inhibition of other translation factors, including the mRNA helicase eIF4A [6,7]. SGs are large non-membrane bound cytoplasmic entities that contain mRNAs, translation initiation complexes and other RNA-binding proteins (RNPs) [3, 8]. Stress-induced

Edited by D. Aberdam

Electronic supplementary material The online version of this article (https://doi.org/10.1038/s41418-018-0076-9) contains supplementary material, which is available to authorised users.

Alan J. Whitmarsh

alan.j.whitmarsh@manchester.ac.uk

1 School of Biological Sciences, Faculty of Biology, Medicine and Health, University of Manchester, Manchester Academic Health Science Centre, Michael Smith Building, Oxford Road, Manchester M13 9PT, UK

2 Laboratory of Therapeutic Innovation (UMR 7200), CNRS, University of Strasbourg, 67401 Illkirch, France translation inhibition leads to specific RNPs binding to stalled mRNAs in translation complexes and nucleating SGs by promoting transient interactions between their disordered regions [8-12]. Recent studies have indicated that SGs exist as liquid droplets with a solid core surrounded by a fluid shell and that they form via liquid-liquid phase separation dependent upon the local concentration of mRNAs and RNPs [13-17]. SGs are highly dynamic, triaging and storing mRNAs to enable cells to re-programme translation and mount a protective response $[3,8,18]$. In addition, there is accumulating evidence that SGs regulate cellular signalling pathways to coordinate changes in translation with altered cell fate $[4,19,20]$. Recent studies have indicated that the interplay between the mechanistic target of rapamycin (mTOR) pathway and SGs is important for regulating cell fate [21-23].

The mTOR protein kinase is a component of the mTORC1 complex that targets many proteins involved in translation [24]. It phosphorylates and inactivates 4EBP proteins causing them to release eIF4E for binding to eIF4G1 and thus permitting translation initiation [24]. It also phosphorylates the p70 S6 kinases S6K1 and S6K2, leading to their activation and phosphorylation of substrates that promote translation initiation, including S6 ribosomal protein (RPS6) [24]. In yeast, TORC1 activity is suppressed by its sequestration into SGs following heat stress and this protects against DNA damage [21]. Similarly, mTORC1 components are sequestered into mammalian SGs, resulting 
in reduced mTORC1 assembly and suppression of mTORC1 hyperactivation-induced apoptosis [22, 23]. Whilst the actions of mTORC1 can be inhibited by SGs, paradoxically, there is evidence that $\mathrm{mTORC} 1$ can suppress translation and facilitate SG assembly [25, 26]. Thus, it is important to gain a better understanding of the complex role of the mTOR pathway in SG dynamics. In this study, we demonstrate that the mTORC1 effector kinases S6K1 and S6K2 have distinct roles in SG assembly and maintenance in cultured human cells and that the S6 kinase orthologue, RSKS-1, promotes SG assembly in Caenorhabditis elegans.

\section{Results}

\section{S6K1 and S6K2 localise to SGs}

Consistent with previous studies [22, 23], we observed the localisation of the mTORC1 associated proteins mTOR, RAPTOR and ASTRIN with the SG marker G3BP1 in HeLa cells treated with $0.5 \mathrm{mM}$ sodium arsenite for $30 \mathrm{~min}$ to cause an acute oxidative stress (Fig. S1A-C). We also observed robust localisation of $\mathrm{S} 6 \mathrm{~K} 2$ to $\mathrm{SG}$ with less pronounced co-localisation of $\mathrm{S} 6 \mathrm{~K} 1$ and the S6 kinase substrate RPS6 (Fig. 1a, S1D). Sodium arsenite treatment causes translational repression and SG formation via promoting the phosphorylation of Ser51 on eIF2 $\alpha$ [27] but SGs also form independent of this following inhibition of eIF4A $[6,7]$. We found that mTORC1 components, S6 kinases and RPS6 all localised to SGs following treatment with FL3, an eIF4A inhibitor [28, 29] (Fig. 1a, S1). As expected, FL3 suppressed translation without increasing eIF2 $\alpha$ phosphorylation (Fig. S2). We conclude that S6K2, and to a lesser extent S6K1, are present in SGs formed by both eIF2 $\alpha$ phosphorylation-dependent and independent mechanisms. The acute oxidative stress induced by high concentrations of sodium arsenite (e.g., $0.5 \mathrm{mM}$ ) may not be reflective of physiological conditions, so we investigated the formation of SGs under milder oxidative stress. Cells were treated with $30 \mu \mathrm{M}$ sodium arsenite for up to $6 \mathrm{~h}$ and assessed for SG formation by immunostaining for the SG marker proteins G3BP1 and TIA1 (Fig. 1b). SG formation increased up to $2 \mathrm{~h}$ of treatment before declining (Fig. 1b-d) and this temporal profile correlated with the abundance of phosphorylated eIF $2 \alpha$ (Fig. 1e). To determine how the changes in phospho-eIF $2 \alpha$ levels were related to translational inhibition, we performed a puromycin incorporation assay [30]. Puromycin acts as an analogue of aminoacyltRNA and we found that its incorporation into newly synthesised proteins inversely correlated with phospho-eIF2 $\alpha$ levels across the time course (Fig. 1f), indicating that mild oxidative stress promotes the phosphorylation of eIF2 $\alpha$ coincident with decreased translation. Interestingly, cells subjected to $30 \mu \mathrm{M}$ sodium arsenite for $24 \mathrm{~h}$ still displayed SGs (Fig. S3A), suggesting that SG formation may be oscillatory with a peak at $2 \mathrm{~h}$, declining by $6 \mathrm{~h}$, but with SGs re-appearing in most cells by $24 \mathrm{~h}$. Importantly, we found that the SGs formed after mild arsenite stress have distinct characteristics compared to those induced by acute arsenite treatment. The aliphatic alcohol 1,6-hexanediol dissolves liquid structures by breaking weak hydrophobic bonds while leaving solid aggregates unaffected [14, 31], thus can distinguish between the liquid phase and solid aggregates within SGs. It is reported that high concentrations of this reagent induces SGs [18], so we used a concentration $(0.5 \%)$ that we determined does not promote granule formation. Under these conditions, there was a decrease in the size of SGs formed after mild arsenite treatment but not after acute treatment (Fig. S4A-C), suggesting that SGs induced by mild oxidative stress contain a higher liquid composition. Further evidence that SGs formed after mild oxidative stress are distinct came from the use of ISRIB, which inhibits the actions of phosphorylated eIF2 $\alpha$ [27]. SG formation under mild arsenite treatment was suppressed by ISRIB but this did not occur in response to the acute stress (Figs. S4D, E). Together, these data suggest that distinct types of SGs exist dependent on the level of oxidative stress. We found that S6K1 was significantly more abundant in SGs formed after mild arsenite treatment compared to those formed following acute arsenite stress, whilst S6K2 showed robust localisation to SGs in both conditions (Fig. 1a, g, S3B). Furthermore, the different isoforms of S6K1 and S6K2 [32, 33] all localised to SGs in response to mild arsenite treatment when ectopically expressed in HeLa cells (Fig. S5). Our data demonstrate that S6 kinases accumulate in distinct SGs formed following mild oxidative stress.

\section{S6K1 and S6K2 are required for SG formation}

We next determined if S6 kinases played a role in regulating SG dynamics. Treatment with LYS6K2, an inhibitor of S6 kinase activity [34], caused a decrease in cells displaying SGs in response to mild arsenite stress (Fig. 2a, S6A, B). To confirm the importance of S6 kinases for SG assembly and investigate the specific roles of S6K1 and S6K2, their expression was knocked-down using siRNA (Fig. 2b, S6C). S6K1 depletion decreased SG number and size after mild arsenite treatment, as judged by immunostaining for the SG marker proteins G3BP1 and TIA1 (Fig. 2c, f-h, S7). S6K2 depletion caused a more modest decrease in the number of cells displaying SGs after $2 \mathrm{~h}$ of arsenite treatment (Fig. 2d, S7), but there were fewer granules per cell and they were smaller than in control cells (Fig. $2 \mathrm{f}-\mathrm{h}, \mathrm{S} 7$ ). At later time points of arsenite treatment, S6K2 depletion did significantly decrease the number of cells with SGs (Fig. 2d, 

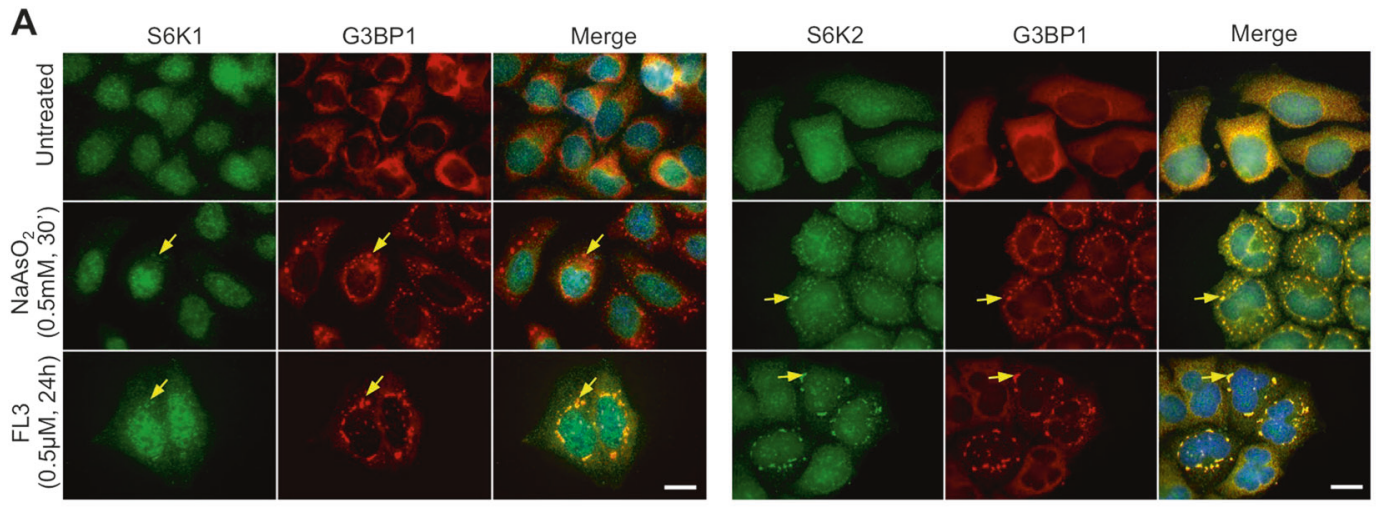

B

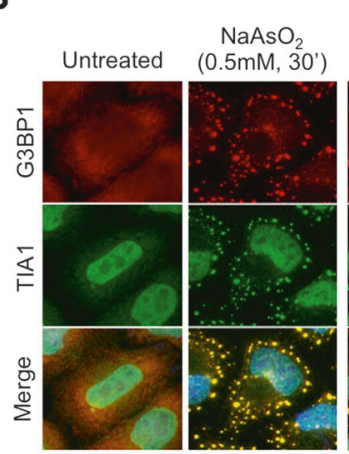

E

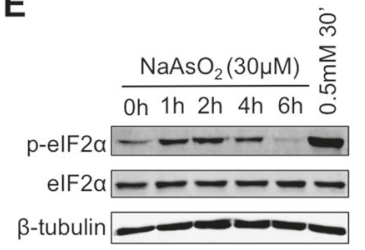

$\mathrm{F}$

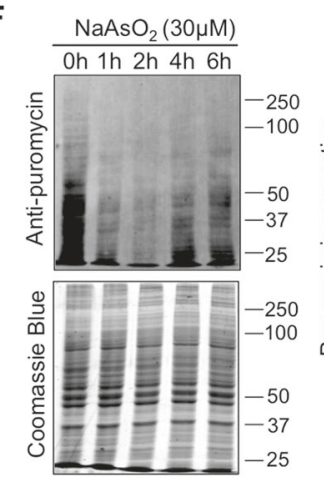

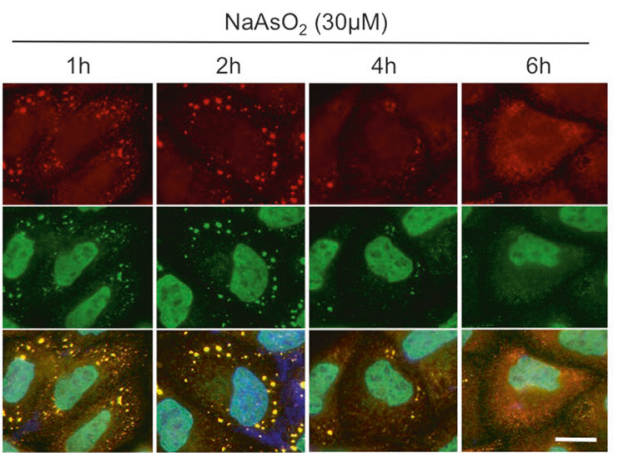

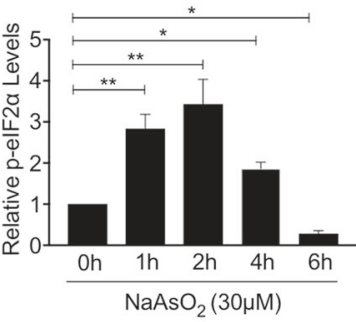

G
C
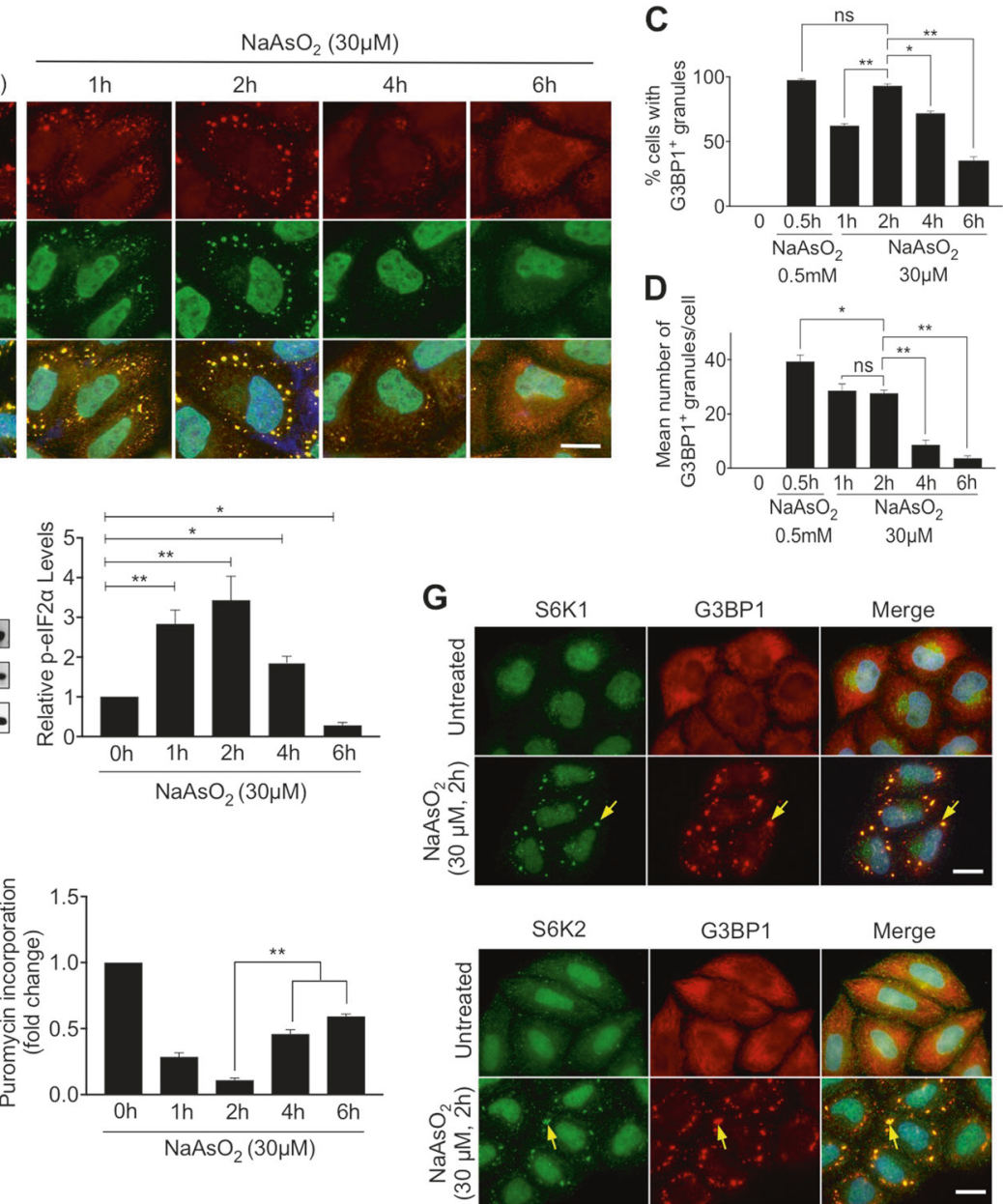

S7C). The depletion of both S6K1 and S6K2 together did not produce an accumulative effect on SG formation or size (Fig. 2e-h). Importantly, the depletion of either S6K1 or S6K2 did not affect SG formation in response to acute arsenite stress (Fig. S8A-D). In conclusion, S6K1 and S6K2 are both required for SG assembly in response to mild oxidative stress. To determine if they also regulate SG assembly in response to other stimuli, we performed a similar analysis using heat stress and the eIF4A inhibitor,
FL3. We found that S6K1 knockdown significantly decreased the number of cells with SGs and SG size in response to heat, while S6K2 knockdown only impacted on SG size (Fig. S9). In contrast, knockdown of S6K1 did not affect SG formation in response to FL3, while S6K2 knockdown reduced the number of cells displaying SGs as well as their size (Fig. S10). Our data suggest that S6 kinases play distinct roles in SG assembly dependent on the type of stress. 
Fig. 1 S6 kinases accumulate in stress granules. a HeLa cells were treated with either $0.5 \mathrm{mM}$ of $\mathrm{NaAsO}_{2}$ for 30 min or $0.5 \mu \mathrm{M}$ FL3 for $24 \mathrm{~h}$ and stress granules labelled using an antibody against G3BP1 (red). The localisation of S6K1 and S6K2 were observed by immunofluorescence staining (green). Nuclei were stained with DAPI (blue). Merged images are shown. Yellow arrows indicate examples of stress granules. Scale bar $=25 \mu \mathrm{m}$. b HeLa cells were treated with either 0.5 $\mathrm{mM}$ of $\mathrm{NaAsO}_{2}$ for $30 \mathrm{~min}$ or $30 \mu \mathrm{M} \mathrm{NaAsO}$ for $1,2,4$ or $6 \mathrm{~h}$. Stress granule formation was assessed by immunofluorescence staining of G3BP1 (red) or TIA1 (green). c, d Quantification of the \% of cells containing stress granules after treatment and the mean number of stress granules in the cells displaying stress granules. 100 cells were counted in each of the 3 biological repeats. Scale bar $=20 \mu \mathrm{m}$. e HeLa cells were treated with either $0.5 \mathrm{mM}$ of $\mathrm{NaAsO}_{2}$ for $30 \mathrm{~min}$ or $30 \mu \mathrm{M}$ $\mathrm{NaAsO}_{2}$ for $1,2,4$ or $6 \mathrm{~h}$ and protein extracts immunoblotted for phosphorylated eIF $2 \alpha$ (p-eIF $2 \alpha$ ), eIF $2 \alpha$ and $\beta$-tubulin. Quantification was performed from three independent experiments. f HeLa cells were treated with $30 \mu \mathrm{M} \mathrm{NaAsO}$ for $1,2,4$ or $6 \mathrm{~h}$. In the last 5 min of treatment, cells were incubated with $5 \mu \mathrm{g} / \mathrm{ml}$ puromycin. Incorporation of puromycin into newly synthesised protein was assessed by immunoblotting. Band intensities for each lane were measured in the biological repeats and normalised against intensity of Coomassie Blue staining. For $\mathbf{c}-\mathbf{f}$, error bars are s.e.m and the data were analysed using one-way Anova $(* p<0.04 ; * * p<0.0002)$. g HeLa cells were treated with $30 \mu \mathrm{M} \mathrm{NaAsO}$ for $2 \mathrm{~h}$ and stress granules were observed by immunofluorescence staining of G3BP1 (red). The distribution of S6K1 and S6K2 were analysed by immunostaining (green). Yellow arrows indicate examples of stress granules. Nuclei were stained with DAPI (blue). Scale bar $=25 \mu \mathrm{m}$

\section{S6K2 promotes SG persistence}

Our observation that S6K2 knockdown caused only a partial reduction in the number of cells with SGs after $2 \mathrm{~h}$ of mild arsenite treatment, but a robust decrease after longer treatments (Fig. 2d), led us to speculate that it might play a more predominant role in maintaining SGs. To address this, we ectopically expressed S6K1p70 or S6K2p54 isoforms in cells (Fig. 3a-c). Even in the absence of arsenite treatment, around $10 \%$ of the S6K1-expressing cells and $25 \%$ of S6K2-expressing cells displayed SGs (Fig. 3d, S5F, S11). After $2 \mathrm{~h}$ of $30 \mu \mathrm{M}$ arsenite treatment, around $75 \%$ of control cells formed SGs and this was enhanced in S6K1and S6K2-expressing cells (Fig. 3d). However, the number of control and S6K1-expressing cells displaying SGs decreased at later time points, but SGs remained present in all the S6K2-expressing cells (Fig. 3d, S11). To determine if S6K2 could maintain SGs after stress removal, cells were treated with $30 \mu \mathrm{M}$ arsenite for $1 \mathrm{~h}$ and left to recover. SGs persisted in the S6K2-expressing cells compared to the control cells in which the SGs rapidly dissolved (Fig. 3g). S6K1-expressing cells displayed a modest effect on maintaining SGs during the recovery period (Fig. $3 \mathrm{~g}$ ). These data suggest that $\mathrm{S} 6 \mathrm{~K} 2$ may play a major role in promoting the persistence of SGs.

\section{S6 kinases promote SG assembly dependent upon their kinase activity}

The observations that mild oxidative stress and FL3 treatment both increase S6 kinase activity (Fig. S12) and that an S6 kinase inhibitor reduces SG formation (Fig. 2a) strongly suggests a key enzymatic role for S6 kinases in SG regulation. In support of this, ectopic expression of a kinaseinactive form of S6K1p70 did not support SG assembly or persistence in response to mild arsenite stress (Fig. 3e, f, h, i, S11). However, around $25 \%$ of cells expressing kinaseinactive S6K2 still displayed SGs, although the number in each cell was reduced (Fig. 3e, f, S11). Furthermore, SG persistence after arsenite withdrawal was only partially suppressed by kinase-inactive S6K2 (Fig. 3h, i, S11). This suggests that S6K2 may have both kinase-dependent and kinase-independent roles in SG regulation. We next investigated how the ectopic expression of the S6 kinases affected the response to FL3. We found that S6K2, but not S6K1, strongly promoted SG formation in the presence of FL3 and this was dependent on S6K2 kinase activity (Fig. S13). This supports our data from knockdown experiments demonstrating that S6K2, but not S6K1, can regulate $\mathrm{SG}$ assembly and persistence in response to eIF4A inhibition (Fig. S10). Taken together, these data suggest that the enzymatic activity of S6 kinases is important for promoting SG assembly and persistence.

\section{Signalling by mTORC1 promotes SG formation}

S6 kinases are downstream targets of mTORC1 and the treatment of cells with the mTORC1 inhibitor rapamycin or knockdown of the mTORC1 component RAPTOR decreased S6 kinase activity and the number of cells displaying SGs after mild arsenite treatment (Fig. 4a-d). Rapamycin also suppressed the ability of overexpressed S6K1p70 and S6K2p54 to promote SG assembly and persistence in untreated cells (Fig. 4e, S14). However, it did not affect SG assembly in response to acute arsenite treatment (Fig. S8E$\mathrm{H})$. In the presence of $30 \mu \mathrm{M}$ arsenite for $6 \mathrm{~h}$, a condition where the expression of S6K2 but not S6K1 promotes SG persistence (Fig. 3d), rapamycin caused only a partial decrease in the number of S6K2-expressing cells displaying SGs (Fig. 4f, S14). When arsenite stress was removed and cells allowed to recover, SG persistence was substantially decreased by rapamycin in the S6K2-expressing cells, but not to the level in control or S6K1-expressing cells (Fig. 4g, S14). These results suggest that there are mTORC1dependent and independent roles for S6K2 in promoting SG persistence, consistent with our data indicating a potential kinase-independent function of S6K2 (Fig. 3e, h, i). 
A

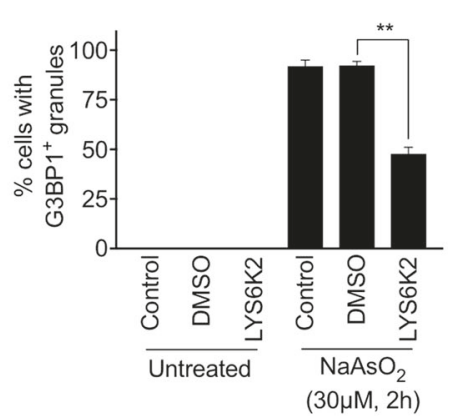

B

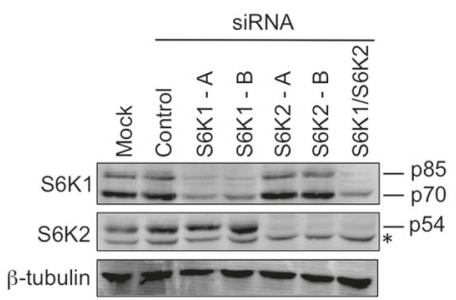

E

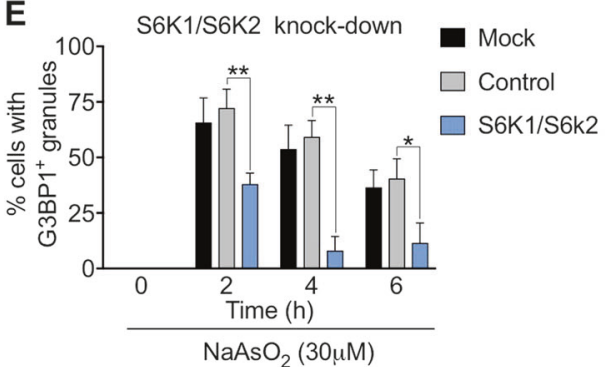

G

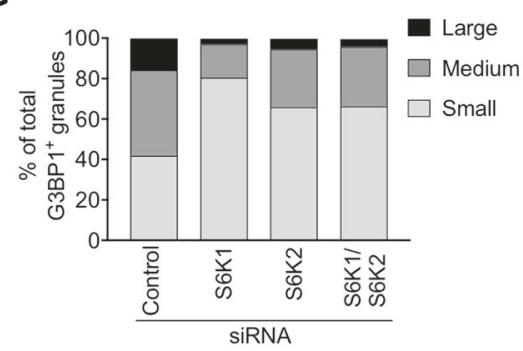

Fig. 2 S6K1 and S6K2 are required for stress granule assembly. a HeLa cells were pre-treated or not with $0.5 \mathrm{mM} \mathrm{LYS6K} 2$ for $12 \mathrm{~h}$ and then treated with or without $30 \mu \mathrm{M}$ of $\mathrm{NaAsO}_{2}$ for $2 \mathrm{~h}$. Quantification of cells with G3BP1-positive granules under the indicated conditions is presented. 100 cells were analysed in each of the 3 biological repeats. Statistical analysis was carried out using one-way Anova $(* * p$ $<0.0002$ ). b HeLa cells were transfected with siRNAs against S6K1 and S6K2 and the levels of knockdown were confirmed via immunoblotting of cell lysates. $\beta$-tubulin levels were analysed to ensure equal loading of lysates. A non-specific band in the S6K2 blot is indicated with a star $(*)$. c-e Quantification of cells with stress granules after treatment with $30 \mu \mathrm{M}$ of $\mathrm{NaAsO}_{2}$ for the indicated times and either siRNAs against S6K1 (S6K1-A and S6K1-B), S6K2 (S6K2-A
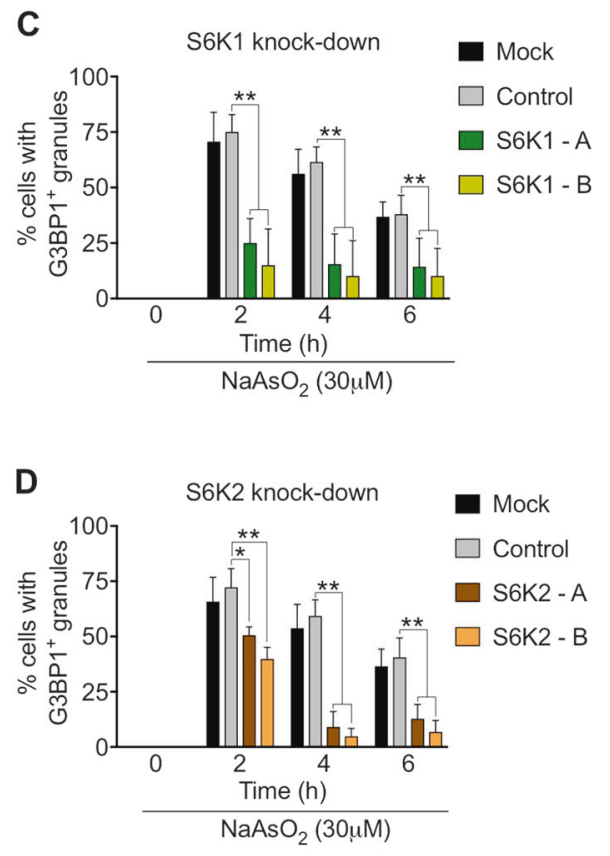

$\mathbf{F}$

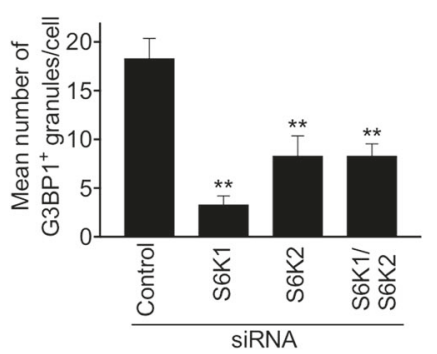

H

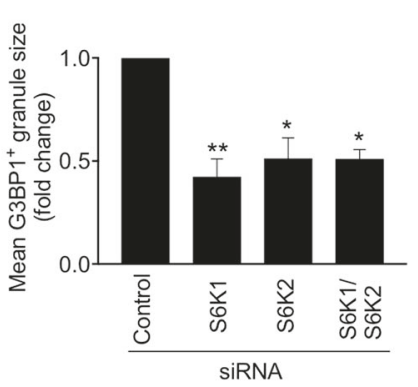

and S6K2-B) or both S6K1 and S6K2 (S6K1-B and S6K2-B). 100 cells were analysed in each of the 4 biological repeats. Error bars are s. e.m. Data were analysed using two-way Anova $(* p<0.04$; ** $p<$ 0.0002). f Mean number of granules per cell in those cells that displayed stress granules after $2 \mathrm{~h}$ treatment with $30 \mu \mathrm{M}$ of $\mathrm{NaAsO}_{2} \cdot \mathbf{g}, \mathbf{h}$ Analysis of the size of stress granules following siRNA knockdown of $\mathrm{S} 6 \mathrm{~K} 1$ or $\mathrm{S} 6 \mathrm{~K} 2$ in cells treated for $2 \mathrm{~h}$ with $30 \mu \mathrm{M}$ of $\mathrm{NaAsO}_{2}$. SGs were clustered into 3 groups according to their size: small, intermediate and large (see Materials and Methods) (g). Mean granule size was also measured (h). 100 cells were analysed in each of the 3 biological repeats. For $\mathbf{f}$ and $\mathbf{h}$, error bars are s.e.m and data were analysed using one-way Anova $(* p<0.04 ; * * p<0.0002)$ 
A

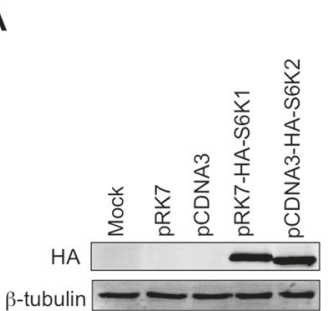

$A$

B

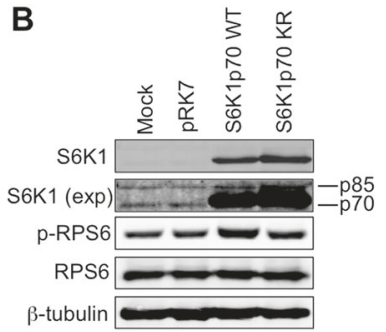

C

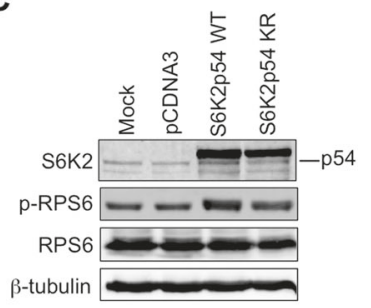

D
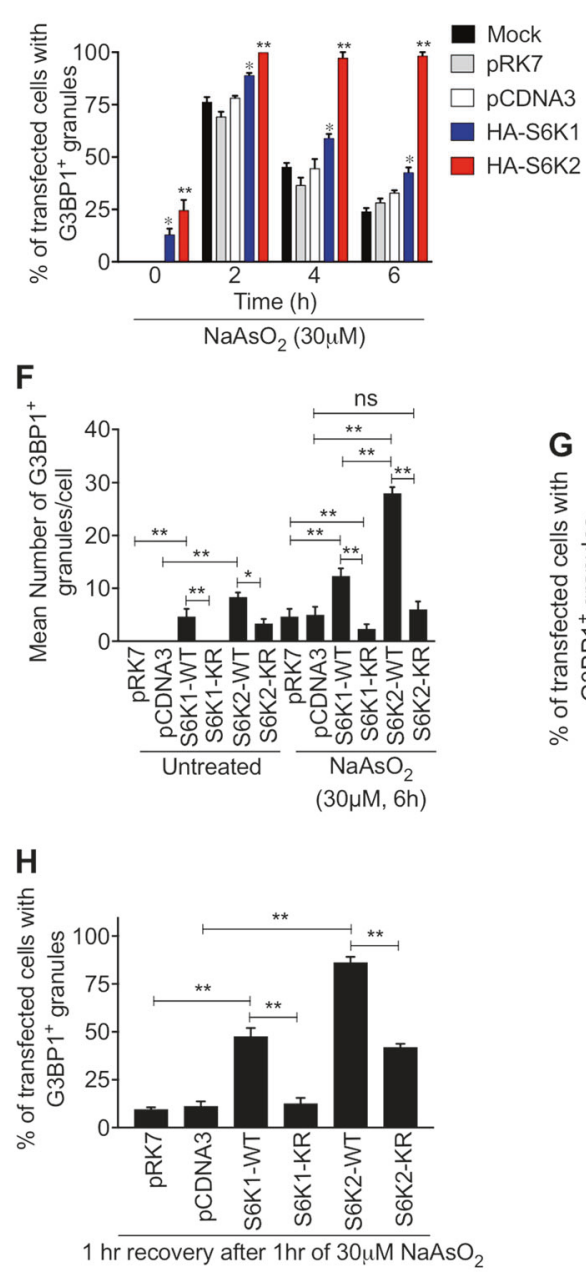

\section{The mTORC1-S6K pathway regulates elF2a phosphorylation and translation initiation in response to mild oxidative stress}

Having established the importance of the mTORC1-S6K pathway for SG assembly and persistence, we investigated how this might occur. Both the inhibition of mTORC1 activity by rapamycin and the depletion of S6K1 or S6K2 led to reduced levels of eIF2 $\alpha$ (Ser51) phosphorylation and suppression of the translation inhibition observed after mild arsenite treatment (Fig. 5a-e). Notably, S6K1 depletion caused a more significant suppression of arsenite-induced
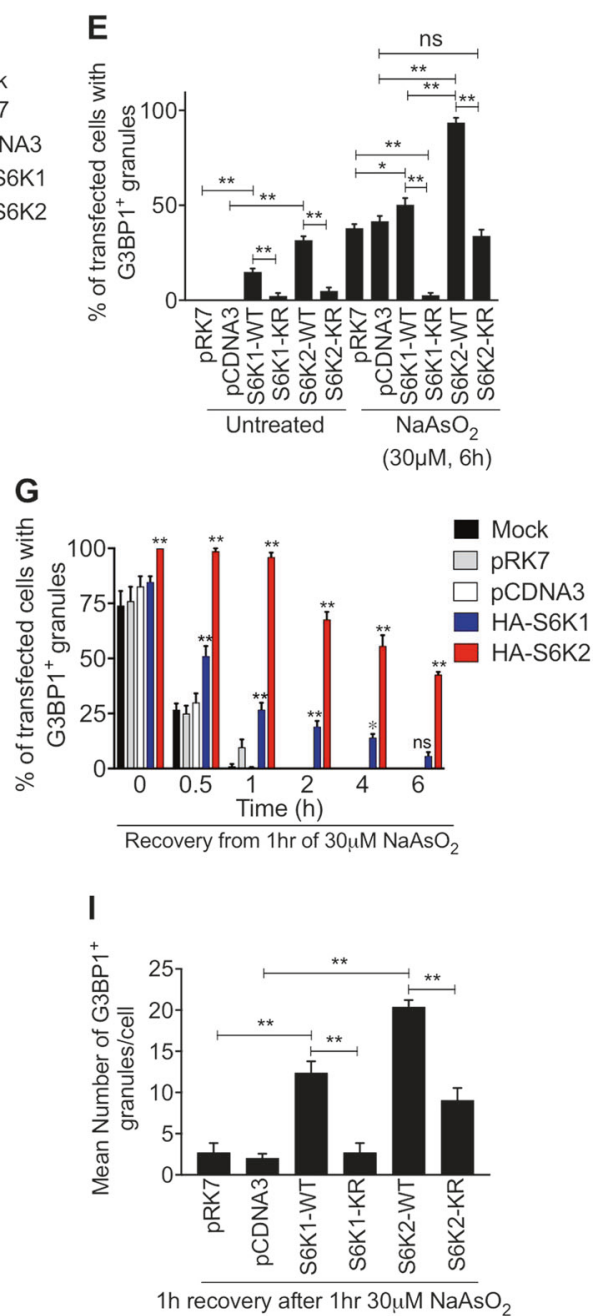

translation inhibition compared to S6K2 depletion (Fig. 5d, e), consistent with the greater suppression of eIF2 $\alpha$ phosphorylation observed after S6K1 depletion (Fig. 5c). Acute arsenite stress led to a robust inhibition of translation that was not affected by depletion of either S6 kinase (Fig. 5c-e), providing further evidence that there are distinct signalling mechanisms promoting SG assembly dependent on the level of oxidative stress. In agreement with the S6 kinase knockdown experiments, ectopic expression of S6K1 or S6K2 increased eIF2 $\alpha$ phosphorylation and partially suppressed translation (Fig. 5f, g, S15). Taken together, our findings indicate that the mTORC1-S6K pathway 
Fig. 3 S6 kinases promote stress granule assembly and persistence dependent on their kinase activities. a-c Immunoblots of lysates from HeLa cells expressing HA-tagged S6K1p70 or S6K2p54 and corresponding kinase-inactive versions (KR). $\beta$-tubulin levels were analysed to ensure equal loading of lysates. Transfection with the parent vectors pRK7 and pCDNA3 was used as a control. Representative blots using antibodies against the HA-tag (a), S6K1 (b) and S6K2 (c) are shown. Comparison between the levels of ectopically expressed and endogenous S6K1 and S6K2 can be observed. The endogenous S6K1 (p85 and p70) can be observed in a longer exposure of the S6K1 blot (exp) and the endogenous S6K2 is labelled as p54. Levels of phosphorylated RPS6 (p-RPS6) and RPS6 are also shown. (d) HeLa cells expressing HA-S6K1p70 or HA-S6K2p54 were treated with 30 $\mu \mathrm{M} \mathrm{NaAsO} \mathrm{O}_{2}$ for the indicated times and the $\%$ of cells with stress granules was quantified. e, f HeLa cells expressing HA-S6K1p70, HAS6K2p54 or kinase-inactive mutants (KR) were treated with $30 \mu \mathrm{M}$ $\mathrm{NaAsO}_{2}$ for $6 \mathrm{~h}$. The $\%$ of cells with stress granules (e) and the mean number of granules in the cells that displayed stress granules were quantified (f). g HeLa cells expressing HA-tagged S6K1p70 or S6K2p54 were subjected to $30 \mu \mathrm{M} \mathrm{NaAsO}{ }_{2}$ for $1 \mathrm{~h}$ and left to recover for the indicated times. The $\%$ of cells displaying stress granules was quantified. h, i HeLa cells expressing HA-S6K1p70, HA-S6K2p54 or kinase-inactive mutants (KR) were treated with $30 \mu \mathrm{M} \mathrm{NaAsO} \mathrm{O}_{2}$ for $1 \mathrm{~h}$ and left to recover for $1 \mathrm{~h}$. The \% of cells with stress granules (h) and the mean number of granules in the cells that displayed stress granules were quantified (i). All quantifications are from 100 cells per condition in each of the 3 biological repeats. Error bars are s.e.m. For $\mathbf{d}$ and $\mathbf{g}$, statistical analysis was performed using two-way Anova and for $\mathbf{e}, \mathbf{f}, \mathbf{h}$ and $\mathbf{i}$ by one-way Anova ( $\mathrm{ns}=$ not significant; $* p<0.04$; $* * p<0.0002$ )

may promote $\mathrm{SG}$ assembly in response to mild oxidative stress via eIF $2 \alpha$ phosphorylation. To explore this further, we analysed whether ISRIB further exacerbated the suppression of SG assembly that occurs following S6 kinase knockdown. ISRIB did not further reduce SG formation following S6K1 depletion (Fig. S16), indicative of S6K1 and eIF $2 \alpha$ acting in the same pathway. However, ISRIB did enhance the reduction in SG assembly caused by S6K2 depletion (Fig. S16), suggesting that S6K2 contributes to SG assembly via eIF $2 \alpha$ phosphorylation and additional mechanisms.

\section{The C. elegans S6 kinase orthologue, RSKS-1, promotes assembly of SGs}

Many studies have focussed on the function of SGs in cultured cells, but their role in metazoan stress responses is poorly characterised. Therefore, it was important to determine if S6 kinases were required for SG assembly in vivo. SGs have been characterised in the nematode worm C. elegans and shown to regulate their response to stress [35-38]. C. elegans express a single S6 kinase orthologue, RSKS-1, which we targeted with RNAi. We utlised a reporter strain featuring pharyngeal muscle expression of the SG protein TIAR-2 fused to the fluorescent protein Venus [38]. Previous studies have demonstrated robust formation of SGs in C. elegans in response to heat stress
[37, 38], a condition that requires S6 kinases for optimal SG assembly in HeLa cells (Fig. S9). We therefore determined the effect of the rsks-1(RNAi) on SG formation in C. elegans subjected to heat stress. The number and size of TIAR2 positive granules increased upon heat stress in wild-type nematodes but not after RSKS-1 knockdown (Fig. 6a, b), indicating the requirement for RSKS-1. Furthermore, we employed a loss-of-function strain [39] to demonstrate that RSKS-1 was important for survival in response to heat stress (Fig. 6c), consistent with a previous study [40]. To determine if the increased sensitivity of the $r s k s-1$ mutant worms is due to their inability to efficiently form SGs, we performed an epistasis assay with $g t b p-1$, the orthologue of mamamlian G3BP1. As in mammalian cells, GTBP-1 is required for SG assembly (Fig. S17). Consistent with a role for SGs in protecting $C$. elegans from heat stress, we found that $g t b p-1(R N A i)$ reduced $C$. elegans survival by around $50 \%$ (Fig. 6d). However, when knockdown of GTBP-1 was performed in the rsks-1 mutant, survival was not further decreased (Fig. 6d). This suggests that RSKS-1 and GTBP1 are likely to be acting in the same pathway required for SG assembly. Taken together, these data indicate that promotion of SG formation by S6 kinase plays a role in C. elegans survival during heat stress and are supportive of S6 kinases being evolutionarily conserved mediators of SG assembly.

\section{Discussion}

Recent studies have indicated a complex relationship between mTOR signalling and SGs in mediating cellular responses to stress. mTORC1 components accumulate in SGs leading to suppression of mTORC1 signalling [21-23] whilst, on the other hand, there is evidence that mTORC1 signalling may be important for the formation and maintenance of SGs $[25,26]$. Here, we show that the mTORC1 effector kinases S6K1 and S6K2 play important roles in SG assembly and persistence in human cells and that the S6 kinase orthologue RSKS-1 is required for robust $\mathrm{SG}$ formation and protection from heat stress in C. elegans.

We demonstrate that S6K1 and S6K2 are novel components of SGs (Fig. 1) and this is supported by a recent report showing that ectopically expressed $\mathrm{S} 6 \mathrm{~K} 2$ is present in cytoplasmic granules [41]. Both kinases play a regulatory role in SG assembly in response to mild oxidative stress but not in response to acute stress (Figs. 2 and 3, S8). This is consistent with the distinct properties of SGs under these different conditions, with those formed after mild oxidative stress being more dependent on the actions of phosphorylated eIF $2 \alpha$ and containing a higher liquid content (Fig. 5, S4). Importantly, the roles of S6K1 and S6K2 in SG regulation are distinct. The initial assembly of SGs in response 
A

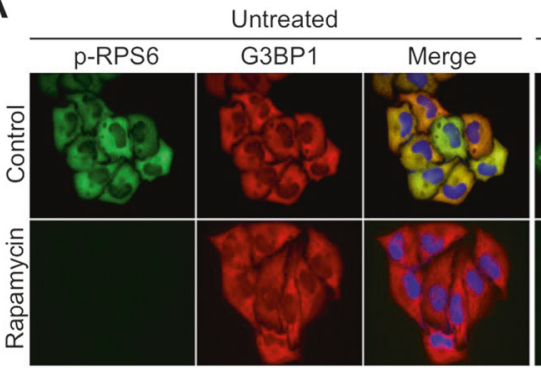

$\mathrm{NaAsO}_{2}(30 \mu \mathrm{M}, 2 \mathrm{~h})$

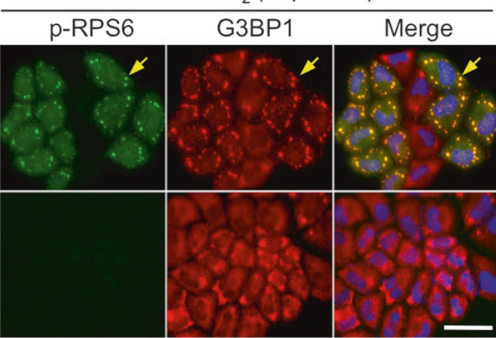

B

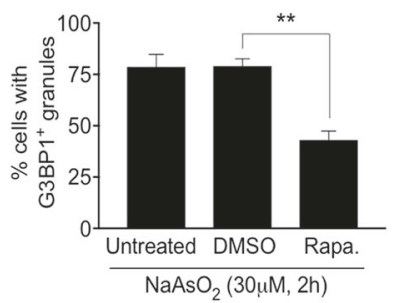

C
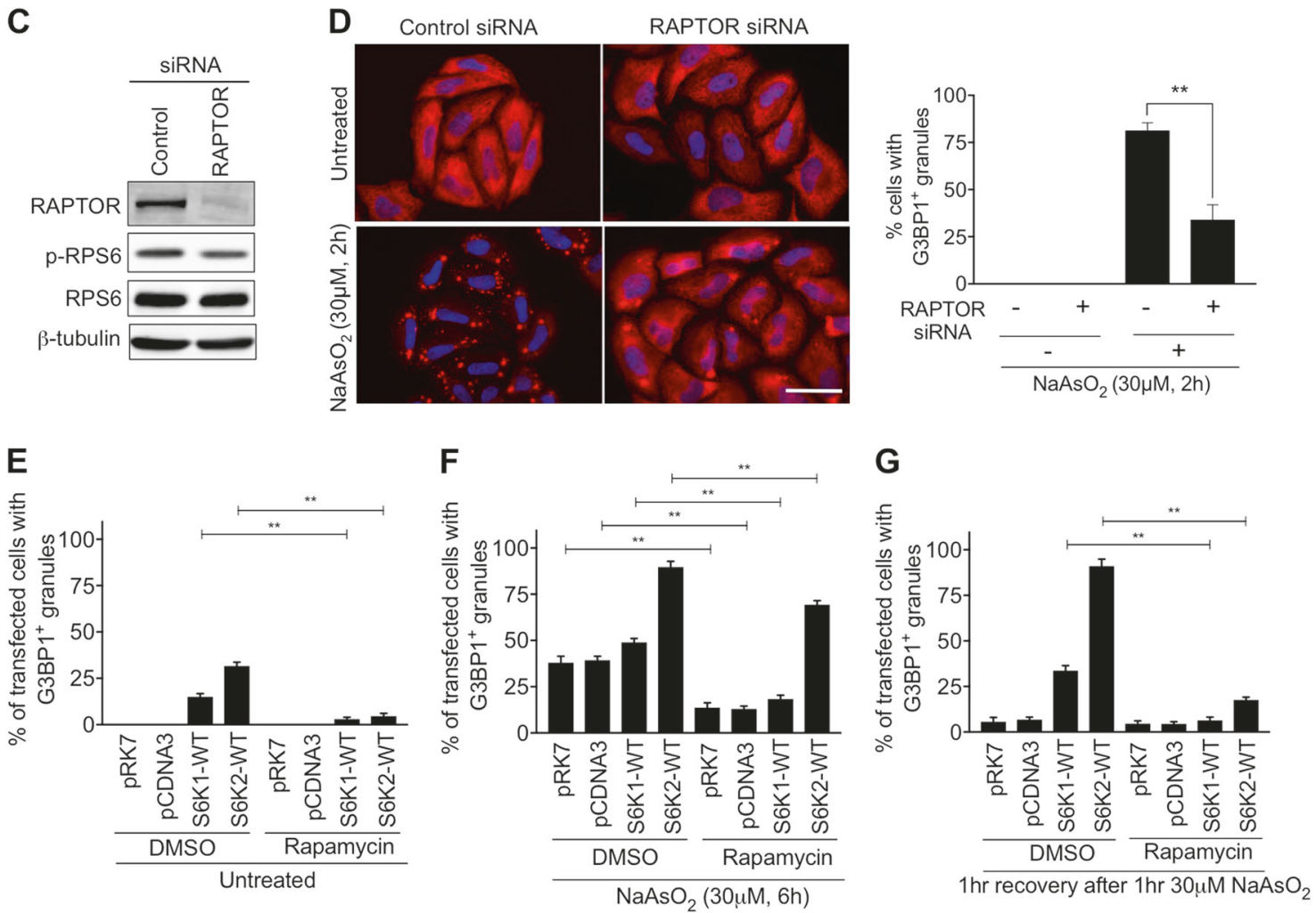

Fig. 4 The mTORC1-S6K signalling pathway is required for stress granule assembly. a HeLa cells were pre-treated with $50 \mathrm{nM}$ Rapamycin for $2 \mathrm{~h}$ prior to exposure to $30 \mu \mathrm{M} \mathrm{NaAsO}$ for a further $2 \mathrm{~h}$. Cells were immunostained for G3BP1 (red) and the phosphorylated form of RPS6 (p-RPS6) (green). Nuclei were stained with DAPI (blue). Yellow arrows indicate examples of stress granules. Scale bar $=25 \mu \mathrm{m}$. b Quantification of cells forming stress granules under the indicated conditions. c HeLa cells were subjected to siRNA directed against RAPTOR. Immunoblots of cell extracts with antibodies to RAPTOR, phosphorylated RPS6 (p-RPS6), RPS6 and $\beta$-tubulin are

to mild oxidative stress appears more dependent on S6K1, whilst S6K2 plays a more predominant role in SG persistence (Figs. 2, 3 and 7) and has both kinase-dependent and kinase-independent functions in SG regulation (Figs. 3 and 4f, g). The knockdown of both S6 kinases together did not further impact on SG formation or persistence (Fig. 2e), possibly due to this causing a more severe translational inhibition that promotes some SG assembly independently of S6 kinases (as occurs in response to high levels of arsenite stress). S6K1, and to a lesser extent shown. d Images of cells treated with or without $30 \mu \mathrm{M} \mathrm{NaAsO}$ for 2 $\mathrm{h}$ and subjected to RAPTOR siRNA. Cells were immunostained for G3BP1 (red). Nuclei were stained with DAPI (blue). Scale bar $=50$ $\mu \mathrm{m}$. Quantification of cells forming stress granules under the indicated conditions is presented. e-g Cells expressing S6K1p70 or S6K2p54 were pre-treated with DMSO or rapamycin for $2 \mathrm{~h}$ and then subjected to either $30 \mu \mathrm{M} \mathrm{NaAsO}{ }_{2}$ for a further $6 \mathrm{~h}$ (f) or $30 \mu \mathrm{M} \mathrm{NaAsO}$ for $1 \mathrm{~h}$ and left to recover for $1 \mathrm{~h}(\mathrm{~g})$. For all quantifications, 100 cells per condition were counted in each of the 3 biological repeats. Error bars are s.e.m. Data were analysed using one-way Anova $(* * p<0.0002)$

S6K2, regulate eIF2 $\alpha$ phosphorylation at Ser51 and the suppression of translation (Fig. 5c-e, S16). HRI kinase is required for eIF2 $\alpha$ phosphorylation in response to arsenite $[5,42]$, so it is possible that S6 kinases promote HRI activity. Alternatively, they may regulate phosphatases that target eIF2 $\alpha$ [43, 44], or promote the binding of eIF2B to phosphorylated eIF $2 \alpha$, by protecting it from dephosphorylation. Whilst we observe a correlation between eIF $2 \alpha$ phosphorylation and translation inhibition, other S6 kinase-dependent mechanisms may also be 
A
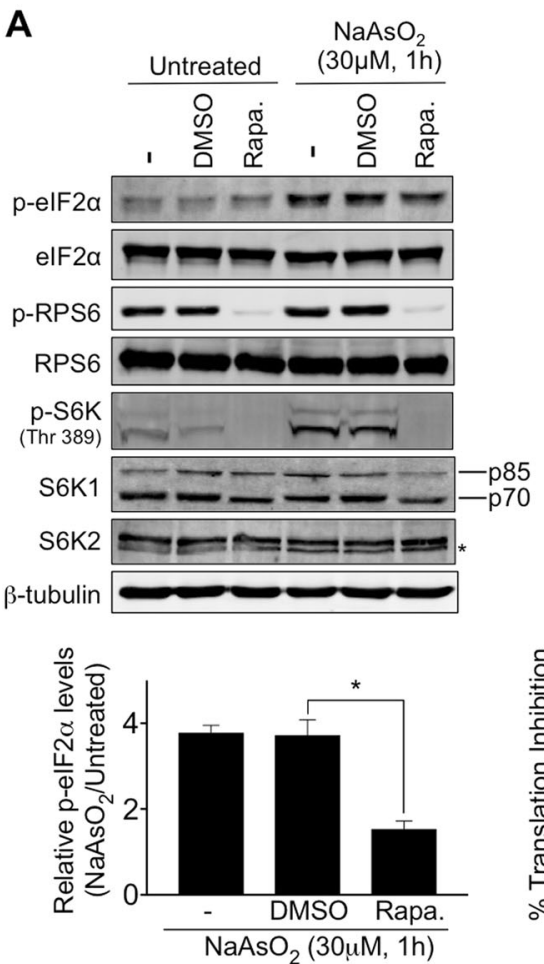

D

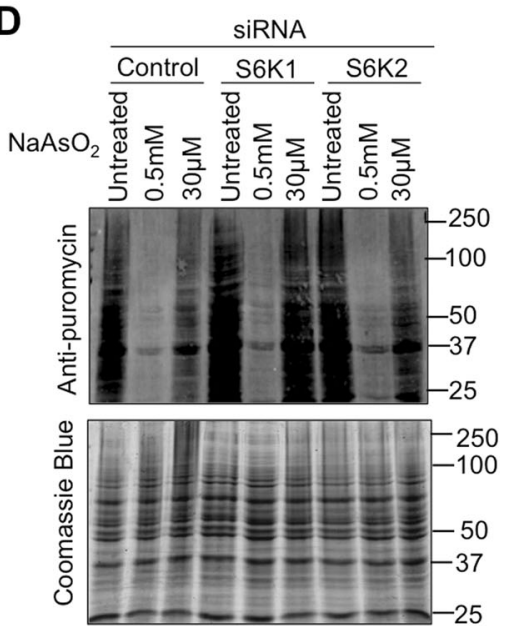

E

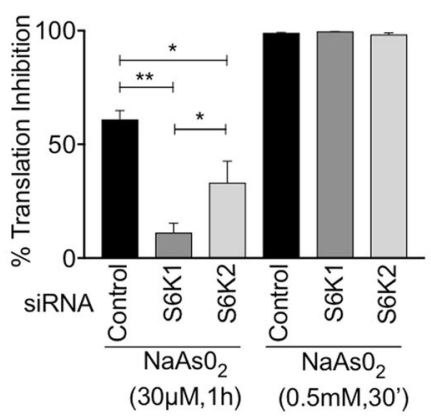

B Untreated $(30 \mu \mathrm{M}, 30$ '

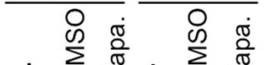

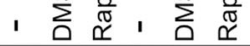
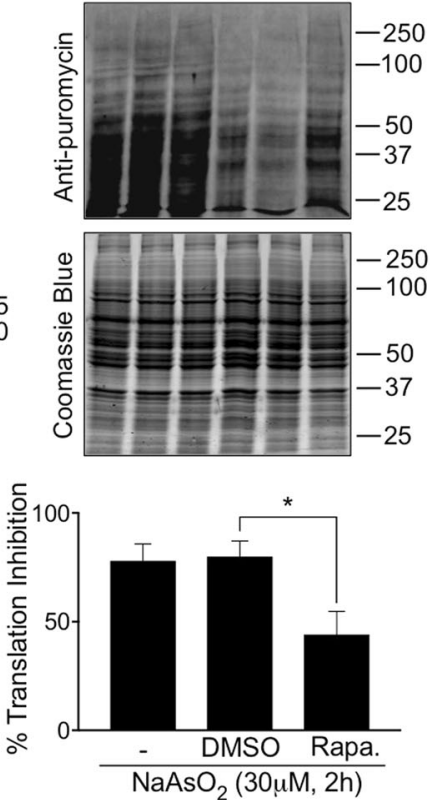

$\mathbf{F}$

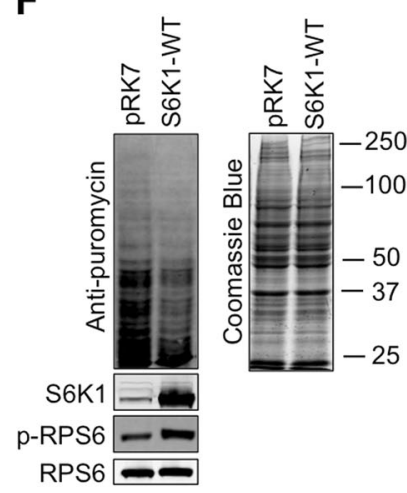

C
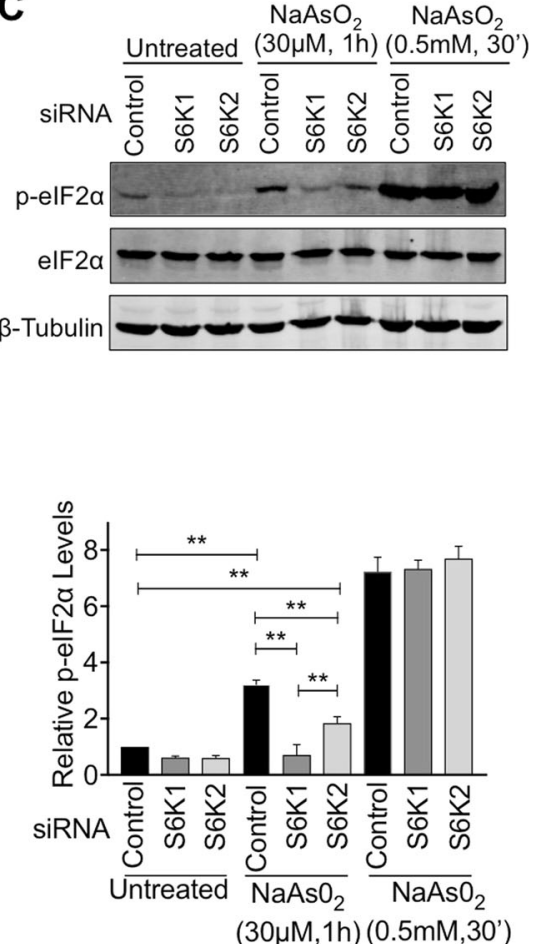

$(30 \mu \mathrm{M}, 1 \mathrm{~h})\left(0.5 \mathrm{mM}, 30^{\prime}\right)$

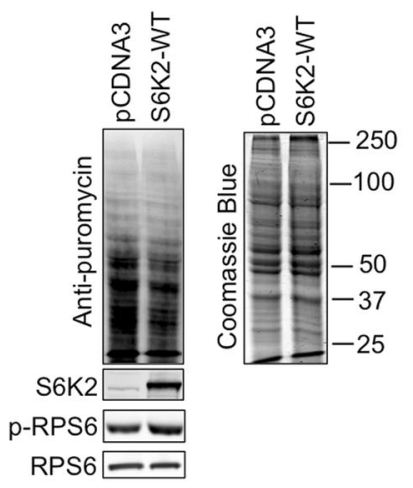

G
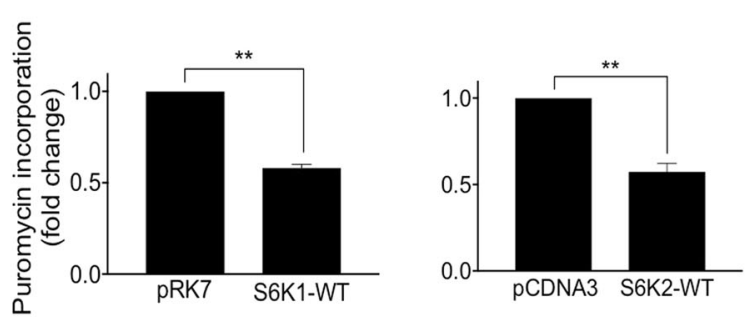

important. For example, it is reported that the phosphorylation of RPS6 by S6 kinases can negatively affect global translation [45], so the reduction in RPS6 phosphorylation caused by the knockdown of S6 kinases could contribute to the suppression of the translation inhibition observed in response to mild oxidative stress. 
Fig. 5 S6 kinases promote the phosphorylation of eIF2 $\alpha$ and translation inhibition. a Immunoblotting of HeLa cell lysates for Ser51 phosphorylation on eIF2 $\alpha$ (p-eIF2 $\alpha$ ) after treating cells with or without $30 \mu \mathrm{M} \mathrm{NaAsO}$ for $1 \mathrm{~h}$ in the presence of either DMSO or $50 \mathrm{nM}$ rapamycin. Levels of phosphorylated RPS6 (p-RPS6) and S6 kinases (p-S6K) are shown to indicate the effectiveness of rapamycin at inhibiting mTORC1 activity. Blots for total eIF2 $\alpha$, RPS6, S6K1 and S6K2 protein levels are also presented. Quantification of p-eIF $2 \alpha$ band intensities from 4 independent experiments is shown. The p-eIF2 $\alpha$ levels were normalised against $\beta$-tubulin levels and are presented as relative increase in phosphorylation between untreated samples and those treated with $\mathrm{NaAsO}_{2}$. b HeLa cells were treated with $30 \mu \mathrm{M}$ $\mathrm{NaAsO}_{2}$ for $30 \mathrm{~min}$ and the incorporation of puromycin into newly synthesised protein was assessed by immunoblotting. Band intensities for each lane were measured in 4 independent experiments and normalised against the intensity of Coomassie blue staining and presented as \% translation inhibition. c HeLa cells transfected with siRNAs against S6K1 or S6K2 were treated with either $30 \mu \mathrm{M} \mathrm{NaAsO} \mathrm{O}_{2}$ for $1 \mathrm{~h}$ or $0.5 \mathrm{mM} \mathrm{NaAsO}$ for $30 \mathrm{~min}$. Protein extracts were immunoblotted for p-eIF $2 \alpha$ and total eIF $2 \alpha$ protein levels. Quantification of p-eIF2 $\alpha$ band intensities from 5 independent experiments is shown. The peIF $2 \alpha$ levels were normalised against $\beta$-tubulin levels. d, e HeLa cells transfected with siRNAs against S6K1 or S6K2 were treated with either $30 \mu \mathrm{M} \mathrm{NaAsO}$ for $1 \mathrm{~h}$ or $0.5 \mathrm{mM} \mathrm{NaAsO}$ for $30 \mathrm{~min}$ and the incorporation of puromycin into newly synthesised protein was assessed by immunoblotting. Band intensities for each lane were measured in 3 independent experiments and normalised against the intensity of Coomassie blue staining and presented as \% translation inhibition (e). f, $\mathbf{g}$ HeLa cells transfected with empty plasmids or plasmids expressing HA-S6K1p70 or HA-S6K2p54 were assessed for the incorporation of puromycin into newly synthesised protein by immunoblotting. The expression of the S6 kinases increased the levels of phosphorylated RPS6 (p-RPS6). Quantification of puromycin incorporation normalised against the intensity of Coomassie blue staining in 3 independent experiments is presented (g). Error bars are s. e.m and the data analysed using one-way Anova $\left(* p<0.04 ; *^{*} p<\right.$ $0.0002)$

The relative importance of the S6K1 and S6K2 can vary depending on the form of stress. We found that $\mathrm{S} 6 \mathrm{~K} 1$ plays a more dominant role than S6K2 in SG assembly in response to heat stress (Fig. S9) but it is not required for SG formation following inhibition of eIF4A, which is independent of eIF2 $\alpha$ phosphorylation (Fig. S10). This supports the case that S6K1 regulates eIF2 $\alpha$ phosphorylation to promote SG assembly whilst S6K2 has additional actions, indicative of a broader function in SG assembly and persistence. While the precise mechanisms by which $\mathrm{S} 6$ kinases regulate SGs remain to be elucidated, their localisation to SGs suggests they could directly target other SG components. The fluid shell of SGs may provide an environment that promotes specific enzymatic reactions, as well as enhancing protein-protein interactions [17]. Interestingly, S6K2 is reported to phosphorylate hnRNPA1, which re-localises from nuclei to SGs upon arsenite stress [46, 47]. As S6K2 also localises to nuclei (Fig. 1g), it is possible that it may translocate with hnRNPA1 to SGs and they act together to regulate SG assembly or persistence. Such a co-dependency between the protein kinase RSK2 and the SG protein TIA1 in SG assembly has previously been proposed [20].
Overall, our data support an important role for mTORC1 effectors in promoting SG formation and functioning and complements previous research showing that mTORC1 phosphorylation of 4EBP1 was necessary for formation of SGs [25]. However, an important question is how to rationalise the requirement of mTORC1 effectors for SG assembly with the observation that SGs inhibit mTORC1 signalling (Fig. 7) [22, 23]. A possibility is that S6 kinases and 4EBP1 are important for SG assembly and persistence under mild stress conditions, but once the level of stress reaches a certain threshold, then mTORC1 signalling is inhibited to prevent its hyperactivation that can lead to apoptosis. The complex relationship between mTORC1 signalling and SGs may be mirrored in other stress-regulated pathways. For example, the JNK MAP kinase pathway promotes SG formation [48], but JNK activity and apoptosis can be suppressed by the sequestration of the upstream kinase MEKK4 into SGs [19].

SGs are part of a conserved adaptive mechanism to promote survival in response to stressful conditions [3, 4]. Using the multicellular organism C. elegans, we demonstrated that S6 kinase is important for heat-induced SG formation and that this correlates with stress resistance (Fig. 6, S17). Interestingly, the dynamic nature of SGs becomes more restricted with age in $C$. elegans, with the formation of solid aggregates that correlate with decreased fitness [38]. Genetic interventions that restore SG dynamics lead to increased lifespan [38]. Although rsks-1 mutants have increased sensitivity to stress, they display increased lifespan [39, 40], so it is possible RSKS-1 may contribute to the formation of solid SG aggregates during ageing. There is also increasing evidence that SG proteins are important components of aggregates that underpin a number of neurodegenerative disorders [49] and that enhanced mTORC1/ S6 kinase signalling contributes to this [50]. Aberrant regulation of S6 kinases and SGs may also be relevant to other pathologies, including cancer [51-53].

\section{Materials and methods}

\section{Cell culture and SG induction}

HeLa cells (from ATCC) were cultured in Dulbecco's Modified Eagles Medium (D6429, Gibco ${ }^{\circledR}$ Life Technologies) supplemented with $10 \%$ foetal bovine serum (FBS) (S181H, Biowest) and 1\% penicillin-streptomycin solution (P4333, Sigma). Cells were grown at $37^{\circ} \mathrm{C}$ in $5 \% \mathrm{CO}_{2}$. For immunoblotting and immunofluorescence assays, 100,000 cells/well were added to 6-well dishes. For immunofluorescence experiments, cells were grown on cover slips. SGs were induced by addition of $\mathrm{NaAsO}_{2}$ or FL3 at the concentrations indicated in the figure legends. Heat stress 
A
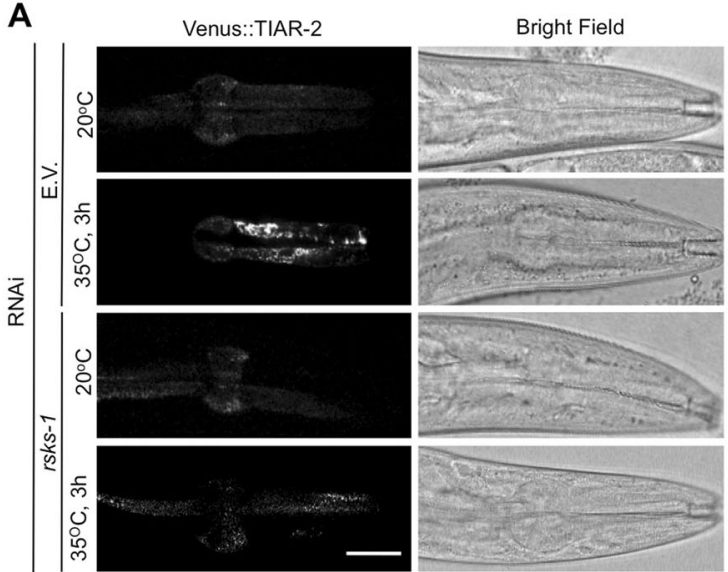

B

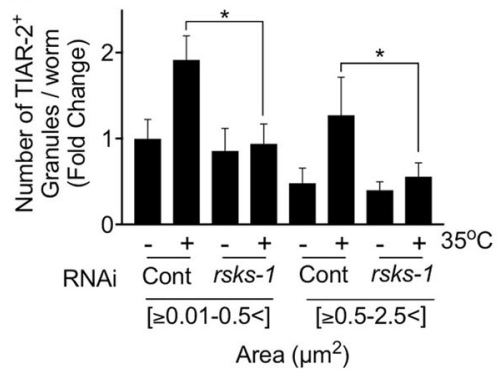

D

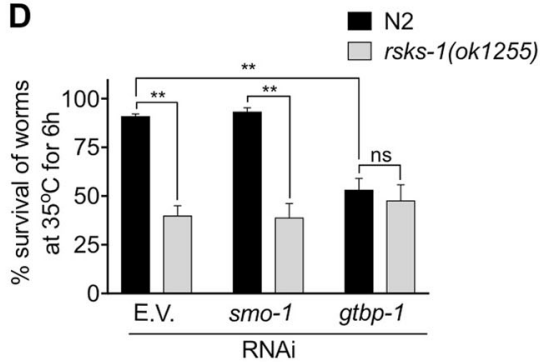

Fig. 6 The C. elegans S6 kinase orthologue, RSKS-1, promotes stress granule formation in vivo. a Worms expressing a pharyngeal Venus:: TIAR-2 reporter were fed $r s k s-1$ RNAi and subjected to heat shock at $35^{\circ} \mathrm{C}$ for $3 \mathrm{~h}$. Images of the pharynx of worms are shown for the indicated conditions. Left-hand panels show reporter expression and the right-hand panels are corresponding bright field images. Scale bar $=25 \mu \mathrm{M}$. $\mathbf{b}$ Quantification of the number of TIAR-2 positive granules separated by size, either small $\left(0.01-0.5 \mu \mathrm{m}^{2}\right)$ or large $\left(0.5-2.5 \mu \mathrm{m}^{2}\right)$. 30 worms were analysed per condition in 3 biological repeats and data analysed by two-way Anova (ns $=$ not significant; $* p<0.04)$. c Worm survival assay. N2 or rsks-1(ok1255) mutant worms were subjected to

was applied by incubating cells at $42{ }^{\circ} \mathrm{C}$ for $1.5 \mathrm{~h}$. Rapamycin (R0395) and ISRIB (SML0843) were obtained from Sigma-Aldrich. LYS6K2 (ab146199) was from Abcam.

\section{Transfection of plasmids and siRNAs}

Plasmids were transfected into cells using JetPEI ${ }^{\circledR}$ (101B010N, Polyplus Transfections) and siRNAs using Lipofectamine ${ }^{\circledR}$ RNAiMAX Transfection Reagent (13778150, Thermofisher Scientific). Cells were incubated overnight in the presence of plasmid or siRNA and the medium was then changed and cells incubated a further $24 \mathrm{~h}$ prior to analysis. Plasmids pRK7-HA-S6K1-WT (\#8984), pRK7-HA-S6K1KR (\#8985), pcDNA3-HA-S6K2p54-WT (\#17729) and pcDNA3-HA-S6K2p54-KR (\#17730) were obtained from Addgene. Plasmids pcDNA3-HA-S6K1p70, pcDNA3-HAS6K1p85 and pcDNA3-HA-S6K2p56 were constructed by the Whitmarsh lab (details on request). Control siRNA (D001810-02-05 and D-001810-02-05), S6K2 siRNA-B (L- heat shock at $35^{\circ} \mathrm{C}$ and the number of worms alive at the indicated times was scored. At least 30 worms were assessed in each of the 3 biological repeats and data were analysed using two-way Anova $\left({ }^{*} p<\right.$ $0.04 ; * * p<0.0002)$. d Epistasis experiment to determine the relationship between $r s k s-1$ and $g t b p-1$. N2 and rsks-1(ok1255) worms were fed with gtbp-1(RNAi) and subjected to heat stress $\left(35^{\circ} \mathrm{C}\right.$ for 6 h). Worm survival was recorded. The smo-1 RNAi was used as a negative control as it does not suppress stress granule assembly. 30 worms were analysed per condition in 3 biological repeats and data were analysed using one-way Anova (ns = not significant; ${ }^{*} p<<$ $0.0002)$

004671-00-0005) and RAPTOR siRNA (J-004107-050002) were from Dharmacon. S6K1 siRNA-A (SI00301721), S6K1 siRNA-B (SI00048608) and S6K2 siRNA-A (SI00288120) were from Qiagen.

\section{Immunoblotting}

Cells were washed with PBS and lysed in Triton lysis buffer (TLB) containing $20 \mathrm{mM}$ Tris-HCl pH 7.4, $137 \mathrm{mM} \mathrm{NaCl}, 2$ mM EDTA, $1 \%$ Triton X-100, $25 \mathrm{mM} \beta$-glycerophosphate, $1 \mathrm{mM} \mathrm{Na}_{3} \mathrm{Va}_{4}, 10 \%$ glycerol, $1 \mathrm{mM}$ phenylmethylsulphonyl fluoride (PMSF), $10 \mu \mathrm{g} / \mathrm{ml}$ aprotinin and $10 \mu \mathrm{g} / \mathrm{ml}$ leupeptin. Protein amount was quantified using the Pierce ${ }^{\mathrm{TM}}$ BCA Protein Assay Kit (Thermo Fisher Scientific) according to manufacturer's protocol. About $25 \mu \mathrm{g}$ of protein lysate was loaded on $10 \%$ polyacrylamide gels and electrophoresis performed at $130 \mathrm{~V}$ for $1.5 \mathrm{~h}$. Resolved proteins were transferred to polyvinylidene difluoride membrane (PVDF, Millipore) using a semidry procedure ( $15 \mathrm{~V}$ for $2 \mathrm{~h}$ ). Membranes 


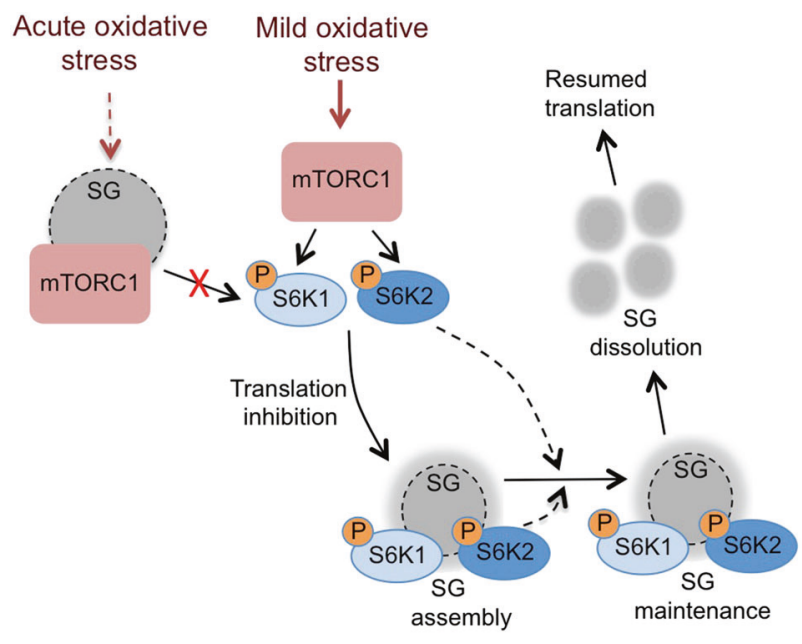

Fig. 7 Schematic of the role of the mTORC1-S6 kinase pathway in stress granule assembly and maintenance. Distinct types of stress granule (SG) are formed depending on the level of oxidative stress. In response to acute oxidative stress, mTORC1 components are sequestered into solid SGs thus inhibiting mTORC1 activity [22, 23]. In response to mild oxidative stress, mTORC1 activates S6 kinases leading to inhibition of translation and the assembly of SGs that contain a solid core surrounded by a liquid shell. Both S6K1 and S6K2 can accumulate in SGs and S6K2 helps maintain SGs via an unknown mechanism. On recovery from the stress, the SGs dissolve and protein translation resumes

were blocked with 5\% BSA in TBST (Tris-buffered saline, $0.2 \%$ Tween-20) and incubated with primary antibodies overnight at $4{ }^{\circ} \mathrm{C}$. Membranes were washed in TBST buffer and incubated for $1 \mathrm{~h}$ at room temperature with secondary antibody diluted in 5\% BSA-TBST supplemented with $0.02 \%$ SDS, prior to washing with TBST buffer and imaging using the Odyssey infrared system (LI-COR Biosciences). Antibodies used are described in Table S1. For phosphoSer51 eIF $2 \alpha$ blots, blocking was performed with 5\% milkTBST at $4{ }^{\circ} \mathrm{C}$ overnight and membranes incubated with primary antibody diluted in 5\% milk-TBST at room temperature for $2 \mathrm{~h}$, prior to washing with TBST and incubation with secondary antibody in 5\% milk-TBST supplemented with $0.02 \%$ SDS. Unprocessed scans of all immunoblots are provided in Figures S19 and S20.

\section{Puromycin incorporation assay}

Performed as described [30]. Puromycin was added to cells for $5 \mathrm{~min}$ at a final concentration of $5 \mu \mathrm{g} / \mathrm{ml}$ prior to harvesting and lysis. The anti-Puromycin antibody (see Table S1 for details) was used at a dilution of 1:25,000.

\section{Immunofluorescence microscopy}

Cells were fixed in $4 \%$ paraformaldehyde for $15 \mathrm{~min}$ at room temperature and permeabilised with PBS buffer containing $0.2 \%$ Triton X-100 (PBST) for $20 \mathrm{~min}$. Cells were blocked with $3 \% \mathrm{BSA}$ in PBST for $30 \mathrm{~min}$ and incubated overnight at $4{ }^{\circ} \mathrm{C}$ with the relevant primary antibodies (see Table S1). Following washes with TBST, cells were incubated in 3\% BSA in PBST solution containing the relevant secondary antibody for $1 \mathrm{~h}$ at room temperature, before further washes in PBST and mounting using the ProLong ${ }^{\circledR}$ Diamond-DAPI (Life Technologies). Imaging was performed with a Leica DM500 B Fluorescence microscope with filter sets for DAPI, FITC and Texas Red. Images were collected with a Leica DCF340 FX camera at a magnification of $60 \times$ and an exposure of 100 ms. Images were processed with Image $\mathbf{J}$ software. A threshold was applied at a value of 142, images shifted to binary and the granules outlined. According to the size of the granules, three groups were identified: small: 0.01-0.6 $\mu \mathrm{m}^{2}$, medium: $0.61-2 \mu \mathrm{m}^{2}$ and large: $2.01-5 \mu \mathrm{m}^{2}$. The mean granule size was also recorded. For co-localisation studies, Pearson's correlation coefficient analysis was performed; 50 cells were analysed in ImageJ for each condition. The colocalisation was assessed using coloc 2 . The data are presented in Figure S18.

\section{C. elegans strains, maintenance and synchronisation}

Strains were grown at $20^{\circ} \mathrm{C}$ on nematode growth media (NGM, $50 \mathrm{mM} \mathrm{NaCl}, 0.25 \%$ (w/v) Bacto-Peptone, $1.7 \%$ (w/v) Agar) supplemented with $\mathrm{CaCl}_{2}(1 \mathrm{mM}), \mathrm{MgSO}_{4}(1$ $\mathrm{mM}), \mathrm{KH}_{2} \mathrm{PO}_{4}(25 \mathrm{mM})$, Cholesterol $(5 \mu \mathrm{g} / \mathrm{ml})$ spotted with OP50 Escherichia coli [54]. Strains used: Bristol N2; rsks-1 (ok1255) RB1206 which is a loss-of-function strain [39] resulting from the deletion of $1700 \mathrm{bp}$ in exon 4 (obtained from the Caenorhabditis Genetics Center); DCD194: N2; uqEx41[Pmyo-2::venus::tiar-2] provided by Della David (German Center for Neurodegenerative Diseases, Tubingen) [38]. To acquire a synchronised population, gravid adults were washed in $15 \mathrm{ml}$ falcon tubes with $\mathrm{M} 9$ buffer $(42 \mathrm{mM}$ $\mathrm{Na}_{2} \mathrm{HPO}_{4} \cdot 12 \mathrm{H}_{2} \mathrm{O}, 22 \mathrm{mM} \mathrm{KH}_{2} \mathrm{PO}_{4}, 86 \mathrm{mM} \mathrm{NaCl}, 1 \mathrm{mM}$ $\mathrm{MgSO}_{4}$ ) and then incubated in $1 \mathrm{ml}$ bleaching solution for 3-4 min ( $8 \mathrm{M} \mathrm{NaOH}, 20 \%$ (v/v) sodium hypochlorite). Resulting embryos were washed in M9 three times and seeded on NGM plates without food.

\section{C. elegans RNAi}

RNAi by feeding was carried out as previously described [55]. Briefly, NGM plates were supplemented with Carbenicillin $(50 \mu \mathrm{g} / \mathrm{ml})$, IPTG $(1 \mathrm{mM})$ and Nystatin $(50 \mathrm{U} / \mathrm{ml})$. Worms were randomly allocated to either control plates with HT115 (DE3) E. coli bacteria transformed with empty L4440 plasmid vector or to plates with HT115 (DE3) E. coli expressing RNAi targeting rsks-1 (ORF-ID Y47D3A.16) and $g$ tbp- 1 (ORF-ID K08F4.2) (purchased from the Vidal 
library of ORF-RNAi available at SourceBioScience). RNAi targeting smo-1 (ORF-ID K12C11.2), the C. elegans orthologue of mammalian SUMOI, was obtained from the Ahringer RNAi library [55] and used as a negative control. Its efficacy was checked by observing known smo-l RNAi phenotypes including low brood size [56]. RNAi vectors were fed to synchronised L4 worms and the F1 generation kept on RNAi until analysis at day 1 of adulthood. The nematodes were placed at $35^{\circ} \mathrm{C}$ for $3 \mathrm{~h}$ and $\mathrm{SG}$ formation was imaged immediately afterwards.

\section{C. elegans imaging}

For live imaging, worms were paralysed in $20 \mathrm{mM}$ tetramisole for 2 min before mounting onto agarose pads. A Leica DM500 B Fluorescence microscope was used with filter sets for DAPI and FITC. Images were collected with a Leica DCF340 FX camera at a magnification of $60 \times$ and an exposure of $100 \mathrm{~ms}$. Images were processed with Image J software. A threshold was applied between values of 130-50, images shifted to binary and the granules outlined. The representative images presented here were obtained using a Leica TCS SP5 AOBS inverted confocal using a $63 \times / 0.6-1.40$ Plan Fluotar objective. The confocal settings were as follows, pinhole [1 airy unit], scan speed $[1000 \mathrm{~Hz}$ unidirectional] and format $[512 \times 512]$ or $[1024 \times 1024]$. Images were collected using PMT detectors with the following detection mirror settings; FITC 494-530 nm using the $488 \mathrm{~nm}(20 \%)$ laser line.

\section{Survival assay}

C. elegans strains were synchronised at day 1 of adulthood and then moved to $35^{\circ} \mathrm{C}$ for the indicated times. Worm viability was assessed by gentle prodding with a platinum wire. At each time point, the total number of worms (alive and dead) was counted and living worms were expressed as a percentage of the total number of worms.

\section{Statistical analysis}

For cell immunofluorescence experiments, statistical analysis was carried out on 3 biological repeats unless otherwise stated. In each repeat, either 50 or 100 cells were counted per sample as stated in figure legends. The analysis was carried out using PRISM software and ordinary one- or two-way Anova. For C. elegans granule size measurements, 30 worms were imaged for the rsks-1 RNAi and 20 worms for the gtbp-1 RNAi and analysed using imageJ. The comparative analysis was carried out using ordinary oneway Anova. For the survival assay, at least 30 worms were counted at each time point in each of the 3 biological repeats and the results were analysed by two-way Anova.
Error bars are s.e.m and variances are similar between the groups being compared and conform to a normal distribution. No statistical method was used to determine the sample sizes. Cells or worms were only excluded from analysis if the images were of insufficient quality.

Acknowledgements We thank Della David (German Center for Neurodegenerative Diseases, Tubingen) for providing the reporter strain DCD194. The $r s k s-1$ (ok1255) RB1206 strain was distributed via CGC (funded by NIH Office of Research Infrastructure Programs [P40 OD010440]) and was originally generated by the C. elegans Gene Knockout Project at the Oklahoma Medical Research Foundation which is part of the International C. elegans Gene Knockout Consortium. We thank members of the Ashe and Whitmarsh labs for helpful discussions. This work was supported by Biotechnology and Biological Sciences Research Council (BBSRC) project grants BB/ K005979/1 and BB/N000757/1 to MPA and BB/J014834/1 and BB/ J014478/1 to AJW and GBP. APS is funded as part of the Wellcome Trust $\mathrm{Ph} . \mathrm{D}$ studentship programme.

\section{Compliance with ethical standards}

Conflict of interest The authors declare that they have no conflict of interest.

Open Access This article is licensed under a Creative Commons Attribution 4.0 International License, which permits use, sharing, adaptation, distribution and reproduction in any medium or format, as long as you give appropriate credit to the original author(s) and the source, provide a link to the Creative Commons license, and indicate if changes were made. The images or other third party material in this article are included in the article's Creative Commons license, unless indicated otherwise in a credit line to the material. If material is not included in the article's Creative Commons license and your intended use is not permitted by statutory regulation or exceeds the permitted use, you will need to obtain permission directly from the copyright holder. To view a copy of this license, visit http://creativecommons. org/licenses/by/4.0/.

\section{References}

1. Kultz D. Molecular and evolutionary basis of the cellular stress response. Annu Rev Physiol. 2005;67:225-57.

2. Spriggs KA, Bushell M, Willis AE. Translational regulation of gene expression during conditions of cell stress. Mol Cell. 2010;40:228-37.

3. Buchan JR, Parker R. Eukaryotic stress granules: the ins and outs of translation. Mol Cell. 2009;36:932-41.

4. Kedersha N, Ivanov P, Anderson P. Stress granules and cell signaling: more than just a passing phase. Trends Biochem Sci. 2013;38:494-506.

5. Aulas A, Fay MM, Lyons SM, Achorn CA, Kedersha N, Anderson P, et al. Stress-specific differences in assembly and composition of stress granules and related foci. J Cell Sci. 2017;130:927-37.

6. Dang Y, Kedersha N, Low WK, Romo D, Gorospe M, Kaufman $\mathrm{R}$, et al. Eukaryotic initiation factor $2 \alpha$-independent pathway of stress granule induction by the natural product pateamine A. J Biol Chem. 2006;281:32870-8.

7. Mazroui R, Sukarieh R, Bordeleau ME, Kaufman RJ, Northcote $\mathrm{P}$, Tanaka $\mathrm{J}$, et al. Inhibition of ribosome recruitment induces stress granule formation independently of eukaryotic initiation factor 2alpha phosphorylation. Mol Biol Cell. 2006;17:4212-9. 
8. Protter DS, Parker R. Principles and properties of stress granules. Trends Cell Biol. 2016;26:668-79.

9. Sama RR, Ward CL, Kaushansky LJ, Lemay N, Ishigaki S, Urano $\mathrm{F}$, et al. FUS/TLS assembles into stress granules and is a prosurvival factor during hyperosmolar stress. J Cell Physiol. 2013;228:2222-31.

10. Tourriere H, Chebli K, Zekri L, Courselaud B, Blanchard JM, Bertrand E, et al. The RasGAP-associated endoribonuclease G3BP assembles stress granules. J Cell Biol. 2003;160:823-31.

11. Gilks N, Kedersha N, Ayodele M, Shen L, Stoecklin G, Dember LM, et al. Stress granule assembly is mediated by prion-like aggregation of TIA-1. Mol Biol Cell. 2004;15:5383-98.

12. Guil S, Long JC, Cáceres JF. hnRNP A1 relocalization to the stress granules reflects a role in the stress response. Mol Cell Biol. 2006;26:5744-58.

13. Brangwynne CP, Eckmann CR, Courson DS, Rybarska A, Hoege $\mathrm{C}$, Gharakhani J, et al. Germline $\mathrm{P}$ granules are liquid droplets that localize by controlled dissolution/condensation. Science. 2009;324:1729-32.

14. Molliex A, Temirov J, Lee J, Coughlin M, Kanagaraj AP, Kim $\mathrm{HJ}$, et al. Phase separation by low complexity domains promotes stress granule assembly and drives pathological fibrillization. Cell. 2015;163:123-33.

15. Lin Y, Protter DS, Rosen MK, Parker R. Formation and maturation of phase-separated liquid droplets by RNA-binding proteins. Mol Cell. 2015;60:208-19.

16. Jain S, Wheeler JR, Walters RW, Agrawal A, Barsic A, Parker R. ATPase-modulated stress granules contain a diverse proteome and substructure. Cell. 2016;164:487-98.

17. Sfakianos AP, Whitmarsh AJ, Ashe MP. Ribonucleoprotein bodies are phased in. Biochem Soc Trans. 2016;44:1411-6.

18. Wheeler JR, Matheny T, Jain S, Abrisch R, Parker R. Distinct stages in stress granule assembly and disassembly. eLife. 2016;5: e18413.

19. Arimoto K, Fukuda H, Imajoh-Ohmi S, Saito H, Takekawa M. Formation of stress granules inhibits apoptosis by suppressing stress-responsive MAPK pathways. Nat Cell Biol. 2008; 10:1324-32.

20. Eisinger-Mathason TSK, Andrade J, Groehler AL, Clark DE, Muratore-Schroeder TL, Pasic L, et al. Codependent functions of RSK2 and the apoptosis-promoting factor TIA-1 in stress granule assembly and cell survival. Mol Cell. 2008;31:722-36.

21. Takahara T, Maeda T. Transient sequestration of TORC1 into stress granules during heat stress. Mol Cell. 2012;47:242-52.

22. Thedieck K, Holzwarth B, Prentzell MT, Boehlke C, Kläsener K, Ruf $\mathrm{S}$, et al. Inhibition of mTORC1 by astrin and stress granules prevents apoptosis in cancer cells. Cell. 2013;154:859-74.

23. Wippich F, Bodenmiller B, Trajkovska MG, Wanka S, Aebersold R, Pelkmans L. Dual specificity kinase DYRK3 couples stress granule condensation/dissolution to mTORC1 signaling. Cell. 2013;152:791-805.

24. Ma XM, Blenis J. Molecular mechanism of mTOR-mediated translational control. Nat Rev Mol Cell Biol. 2009;10:307-18.

25. Fournier MJ, Coudert L, Mellaoui S, Adjibade P, Gareau C, Cote $\mathrm{MF}$, et al. Inactivation of the mTORC1-eukaryotic translation initiation factor 4E pathway alters stress granule formation. Mol Cell Biol. 2013;33:2285-301.

26. Ryu HH, Jun MH, Min KJ, Jang DJ, Lee YS, Kim HK, et al. Autophagy regulates amyotrophic lateral sclerosis-linked fused in sarcoma-positive stress granules in neurons. Neurobiol Aging. 2014;35:2822-31.

27. Sidrauski C, McGeachy AM, Ingolia NT, Walter P. The small molecule ISRIB reverses the effects of eIF $2 \alpha$ phosphorylation on translation and stress granule assembly. eLife. 2015;4:e05033.

28. Thuaud F, Bernard Y, Tukeri G, Dirr R, Aubert G, Cresteil T, et al. Synthetic analogue of rocaglaol displays a potent selective cytotoxicity in cancer cells: involvement of apoptosis inducing factor and caspase-12. J Med Chem. 2009;52:5176-87.

29. Boussemart L, Malka-Mahieu H, Girault I, Allard D, Hemmingsson $\mathrm{O}$, Tomasic $\mathrm{G}$, et al. eIF4F is a nexus of resistance to anti-BRAF and anti-MEK cancer therapies. Nature. 2014;513: 105-9.

30. Panas MD, Kedersha N, McInerney GM. Methods for the characterization of stress granules in virus infected cells. Methods. 2015;90:57-64.

31. Kroschwald S, Maharana S, Mateju D, Malinovska L, Nuske E, Poser I, et al. Promiscuous interactions and protein disaggregates determine the material state of stress-inducible RNP granules. eLife. 2015;4:e06807.

32. Grove JR, Banerjee P, Balasubramanyam A, Coffer PJ, Price DJ, Avruch J, et al. Cloning and expression of two human p70 S6 kinase polypeptides differing only at their amino termini. Mol Cell Biol. 1991;11:5541-50.

33. Pardo OE, Seckl MJ. S6K2: the neglected S6 kinase family member. Front Oncol. 2013;3:191.

34. Li S, Brown MS, Goldstein JL. Bifurcation of insulin signaling pathway in rat liver: mTORC1 required for stimulation of lipogenesis, but not inhibition of gluconeogenesis. Proc Natl Acad Sci USA. 2010;107:3441-6.

35. Jud MC, Czerwinski MJ, Wood MP, Young RA, Gallo CM, Bickel JS, et al. Large P body-like RNPs form in C. elegans oocytes in response to arrested ovulation, heat shock, osmotic stress, and anoxia and are regulated by the major sperm protein pathway. Dev Biol. 2008;318:38-51.

36. Noble SL, Allen BL, Goh LK, Nordick K, Evans TC. Maternal mRNAs are regulated by diverse $\mathrm{P}$ body-related mRNP granules during early Caenorhabditis elegans development. J Cell Biol. 2008;182:559-72.

37. Huelgas-Morales G, Silva-Garcia CG, Salinas LS, Greenstein D, Navarro RE. The stress granule RNA-binding protein TIAR-1 protects female germ cells from heat shock in Caenorhabditis elegans. G3. 2016;6:1031-47.

38. Lechler MC, Crawford ED, Groh N, Widmaier K, Jung R, Kirstein $\mathrm{J}$, et al. Reduced insulin/IGF-1 signaling restores the dynamic properties of key stress granule proteins during ageing. Cell Rep. 2017;18:454-67.

39. Pan KZ, Palter JE, Rogers AN, Olsen A, Chen D, Lithgow GJ, et al. Inhibition of mRNA translation extends lifespan in Caenorhabditis elegans. Aging Cell. 2007;6:111-9.

40. Chen D, Li PW, Goldstein BA, Cai W, Thomas EL, Hubbard AE, et al. Germline signaling mediates the synergistically prolonged longevity produced by double mutations in daf-2 and rsks-1 in $C$. elegans. Cell Rep. 2013;5:1600-10.

41. Pavan IC, Yokoo S, Granato DC, Meneguello L, Carnielli CM, Tavares MR, et al. Different interactomes for p70-S6K1 and p54-S6K2 revealed by proteomic analysis. Proteomics. 2016;16:2650-66.

42. McEwen E, Kedersha N, Song B, Scheuner D, Gilks N, Han A, et al. Heme-regulated inhibitor kinase-mediated phosphorylation of eukaryotic translation initiation factor 2 inhibits translation, induces stress granule formation and mediates survival upon arsenite exposure. J Biol Chem. 2005;280:16925-33.

43. Connor JH, Weiser DC, Li S, Hallenbeck JM, Shenolikar S. Growth arrest and DNA damage inducible protein GADD34 assembles a novel signaling complex containing protein phosphatase 1 and inhibitor 1. Mol Cell Biol. 2001;21:6841-50.

44. Novoa I, Zeng H, Harding HP, Ron D. Feedback inhibition of the unfolded protein response by GADD34-mediated dephosphorylation of eIF2alpha. J Cell Biol. 2001;153:1011-22.

45. Chauvin C, Koka V, Nouschi A, Mieulet V, Hoareau-Aveilla C, Dreazen A, et al. Ribosomal protein S6 kinase activity controls the 
ribosome biogenesis transcriptional program. Oncogene. 2014;33:474-83.

46. Roy R, Durie D, Li H, Liu BQ, Skehel JM, Mauri F, et al. hnRNPA1 couples nuclear export and translation of specific mRNAs downstream of FGF-2/S6K2 signalling. Nucleic Acids Res. 2014;42:12483-97.

47. Kim HJ, Kim NC, Wang YD, Scarborough EA, Moore J, Diaz Z, et al. Mutations in prion-like domains in hnRNPA2B1 and hnRNPA1 cause multisystem proteinopathy and ALS. Nature. 2013;495:467-73.

48. Wasserman T, Katsenelson K, Daniliuc S, Haslin T, Choder M, Aronheim A. A novel c-Jun N-terminal kinase (JNK)-binding protein WDR62 is recruited to stress granules and mediates a nonclassical JNK activation. Mol Biol Cell. 2010;21:117-30.

49. Vanderweyde T, Youmans K, Liu-Yesucevitz L, Wolozin B. Role of stress granules and RNA-binding proteins in neurodegeneration: a mini-review. Gerontology. 2013;59:524-33.

50. Perluigi M, Di Domenico F, Butterfield DA. mTOR signaling in aging and neurodegeneration: at the crossroad between metabolism dysfunction and impairment of autophagy. Neurobiol Dis. 2015;84:39-49.

51. Anderson P, Kedersha N, Ivanov P. Stress granules, $\mathrm{P}$ bodies and cancer. Biochim Biophys Acta. 2015;1849:861-70.

52. Yoshida S, Matsumoto K, Arao T, Taniguchi H, Goto I, Hanafusa $\mathrm{T}$, et al. Gene amplification of ribosomal protein S6 kinase-1 and -2 in gastric cancer. Anticancer Res. 2013;33:469-75.

53. Pérez-Tenorio G, Karlsson E, Waltersson MA, Olsson B, Holmlund B, Nordenskjöld B, et al. Clinical potential of the mTOR targets S6K1 and S6K2 in breast cancer. Breast Cancer Res Treat. 2011;128:713-23.

54. Brenner S. The genetics of Caenorhabditis elegans. Genetics. 1974;77:71-94.

55. Kamath RS, Fraser AG, Dong Y, Poulin G, Durbin R, Gotta M, et al. Systematic functional anlaysis of the Caenorhabditis elegans genome using RNAi. Nature. 2003;421:231-7.

56. Poulin G, Dong Y, Fraser AG, Hopper NA, Ahringer J. Chromatin regulation and sumoylation in the inhibition of Ras-induced vulval development in Caenorhabditis elegans. EMBO J. 2005;24:2613-23. 